\title{
Unique nest entrance structure of Partamona helleri stingless bees leads to remarkable 'crash-landing' behaviour
}

\author{
K. Shackleton ${ }^{1} \cdot$ N. J. Balfour ${ }^{1} \cdot$ H. A. Toufailia ${ }^{1}$ - D. A. Alves ${ }^{2} \cdot$ J. M. Bento ${ }^{2} \cdot$ F. L. W. Ratnieks ${ }^{1}$
}

Received: 5 December 2018 / Revised: 17 May 2019 / Accepted: 23 May 2019 / Published online: 31 May 2019

(c) The Author(s) 2019

\begin{abstract}
Partamona helleri stingless bees construct a unique, funnel-shaped entrance that resolves an evolutionary conflict between foraging efficiency and defence. The large outer entrance allows many foragers to pass while the narrow inner entrance requires few guards to defend. This structure has given rise to a remarkable behaviour in returning foragers, which appear to approach the nest entrance at high speed and 'crash' head first into the entrance. We compared $P$. helleri landing behaviour with two related species with architecturally different entrances that land conventionally using their legs: Melipona scutellaris, whose narrow entrance allows only a single bee to pass, and Scaptotrigona depilis, which has a wide entrance tube. All three species initially decelerated on their approach to the nest entrance. However, $0.2 \mathrm{~m}$ from the entrance $P$. helleri began accelerating, whereas the other species continued to decelerate. Partamona helleri entered its nest at $1.14 \mathrm{~ms}^{-1}$, double the velocity of the other species. Despite its greater velocity, P. helleri made no fewer errors than the other species when attempting to enter its nest, probably by virtue of the large target provided by the outer entrance. We then used a bioassay that suggests that this behaviour is a defence against ambush predators at the nest entrance. Finally, we use a scaling argument to show that the crash impact should not cause any damage to a small animal such as a bee, such that no morphological adaptation is required.
\end{abstract}

Keywords Defence $\cdot$ Insect flight $\cdot$ Social insect $\cdot$ Biomechanics $\cdot$ Speed-accuracy trade-off

\section{Introduction}

Nest building is common across the animal kingdom, and nest location and design are subject to a variety of selective criteria (Wallace 1867; Barber et al. 2001; Hansell 2007; van Casteren et al. 2012; Wenseleers et al. 2013). With few exceptions, eusocial insects build and inhabit nests, which are the central hub for foraging, housing the young and

Electronic supplementary material The online version of this article (https://doi.org/10.1007/s00040-019-00709-9) contains supplementary material, which is available to authorized users.

\section{K. Shackleton}

k.shackleton@sussex.ac.uk

1 Laboratory of Apiculture and Social Insects (LASI), School of Life Sciences, University of Sussex, Brighton BN1 9QG, UK

2 Departamento de Entomologia e Acarologia, Escola Superior de Agricultura "Luiz de Queiroz", Universidade de São Paulo, Av. Pádua Dias 11, Piracicaba, São Paulo 13418-900, Brazil reproductive individuals and often containing food stores (Hölldobler and Wilson 1990; Roubik 2006). The entrance of a social insect nest is of particular importance, because it is where the colony meets the wider environment. This interface is subject to conflicting evolutionary pressures, such as foraging efficiency versus defence. For example, in the stingless bees (Apidae: Meliponini), larger nest entrances allow greater forager traffic but require more guards to defend (Couvillon et al. 2008).

Some social insects, such as Apis mellifera, build their nest in an existing cavity that is chosen according to a set of criteria, and the entrance hole receives little modification (Visscher 2007; List et al. 2009; Seeley 2010). However, in the stingless bees, workers build species-specific entrance structures from mud, wax or resin (Michener 2000; Roubik 2006). One stingless bee genus, Partamona, has been able to finesse the trade-off between foraging and defence through the invention of a unique funnel-shaped entrance (Camargo and Pedro 2003; Fig. 1a): the wide outer entrance of the funnel facilitates forager traffic while the narrow inner entrance requires only a few guards to defend (Couvillon et al. 2008). 
Fig. 1 Nest entrances of the three stingless bee study species from colonies in São Paulo State, Brazil. a Outer funnel entrance of Partamona helleri built from soil and resin, $\mathbf{b}$ narrow entrance hole of Melipona scutellaris built from soil and resin, $\mathbf{c}$ broad entrance tube of Scaptotrigona depilis built of wax and resin. All scale bars, approximately $20 \mathrm{~mm}$. Workers may face ambush predation at the nest entrance, for example by Salticidae jumping spiders on nests of $\mathbf{d} P$. helleri and $\mathbf{e} S$. depilis
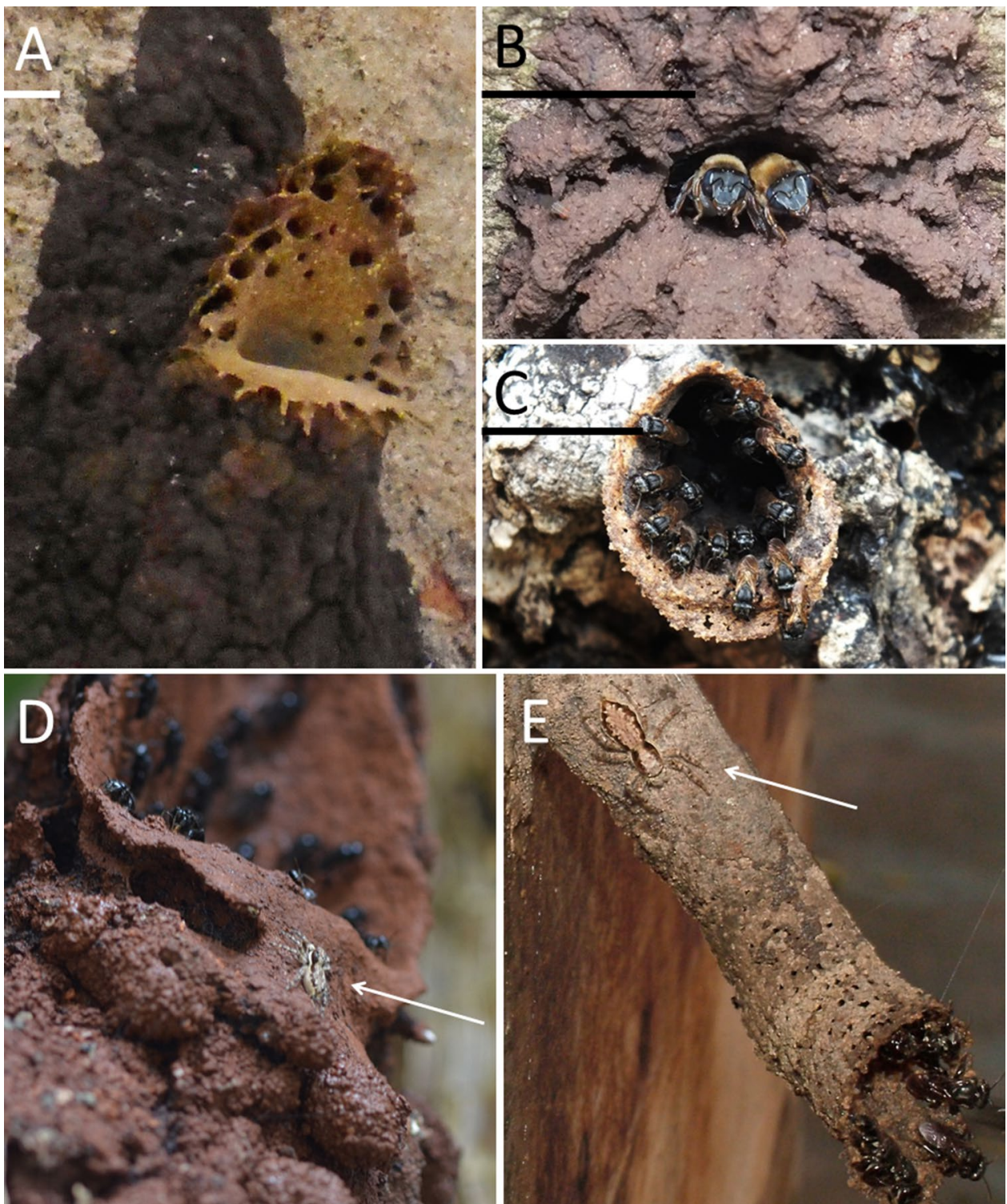

Informal observations of $P$. helleri nests in São Paulo State, Brazil, indicated that their unique entrances were coupled with a remarkable behaviour not seen in other bees-they enter their nest at high speed. Rather than slowing down as they approached the entrance before landing, returning $P$. helleri workers appeared to accelerate. Then, rather than landing conventionally using their legs as undercarriage, workers crashed head first into the wall of the outer entrance funnel and ricocheted down towards the inner entrance (video A1, A2). Chittka et al. (1997) made a similar observation of $P$. pearsoni, noting that bees did not slow down as they approached the entrance. This behaviour is in stark contrast with other flying insects, which gradually decelerate to near zero velocity, hover and extend their legs in a controlled fashion (Srinivasan et al. 2000; Evangelista et al. 2010).
This 'crash-landing' behavioural sequence is unlikely to increase foraging efficiency, because the time saved is likely negligible compared to an entire foraging trip. Another possibility is that it is a predator avoidance mechanism. The nest entrance is a focal point of worker activity, which ambush predators can take advantage of, resulting in significant losses to the colony workforce (Mackay 1982; Schatz and Wcislo 1999). We observed two ambush predator groups on $P$. helleri nests at our study site, Salticidae (jumping spiders, Fig. 1d, e) and Reduviidae (assassin bugs), and workers at nest entrances are also subject to vertebrate predators including Tropidurus spp. lizards (Zacarias 2015). Bees are probably at their most vulnerable to these entrance predators when landing, before they have entered the safety of the nest. However, faster moving prey should be more difficult to capture (van Damme and van Dooren 1999), leading to 
the hypothesis that the acceleratory behaviour of $P$. helleri is a mechanism to escape ambush predation.

This study investigates the crash-landing entrance behaviour of $P$. helleri in four parts. First, we ask the simple questions of how fast do $P$. helleri workers enter their nest, and how does $P$. helleri compare to related species with contrasting entrance structures? To do this, we use Melipona scutellaris which has a narrow entrance through which only one or two bees may pass at a time (Fig. 1b), and Scaptotrigona depilis which has a wide, tubular entrance suitable for high forager traffic (Fig. 1c). Second, we investigate whether this behaviour comes at a cost in terms of making errors when entering the nest. Third, we use a bioassay to test the hypothesis that crash landing has evolved as a predator avoidance mechanism. Finally, we address the biomechanics underlying the crash-landing behaviour.

\section{Methods}

\section{Site description and study species}

The study was carried out on the campus of the University of São Paulo, Luiz de Queiroz College of Agriculture (Escola Superior de Agricultura Luiz de Queiroz, ESALQ), Piracicaba, São Paulo State, Brazil, from 2015 to 2017 during February and March each year. Data were collected when bees were foraging from 06:00 to 11:00 at temperatures of 20-30 ${ }^{\circ} \mathrm{C}$.

We studied colonies of Partamona helleri, Melipona scutellaris and Scaptotrigona depilis. Melipona scutellaris and $S$. depilis were chosen due to their contrasting entrance structures and the local availability of colonies. All $M$. scutellaris and $S$. depilis colonies were housed in hives, while $P$. helleri colonies were in both hives and wild nests. All colonies had constructed their unique nest entrance structures (Fig. 1).

\section{Velocity and acceleration of approaching bees}

A Panasonic DMC-TZ30 camera was set up perpendicular to the approach flights made by bees as they returned to a nest entrance. A white background, either the wall of a building or a piece of plywood, acted as a backdrop against which the dark-coloured bees could be easily seen on the video. The background was marked at $0.1 \mathrm{~m}$ intervals beginning $1.5-1.4 \mathrm{~m}$ from the nest entrance, enabling us to measure the time taken to travel measured distances from the video, and thereby calculate the velocity and acceleration over each interval (see Supplementary Figure A1). We studied at this scale because preliminary observations had shown that most bees were aligned with the entrance and flying directly towards it at this distance. We used the high-speed video setting to record at 220 frames per second (FPS), enabling us to play back the recordings in slow motion and more accurately measure flight velocity. Resolution at these settings was $320 \times 240$ pixels. Filming over a distance of $1.5 \mathrm{~m}$ therefore meant that each pixel represented about $4.7 \mathrm{~mm}$ of horizontal distance. The camera was $5.0 \mathrm{~m}$ from the flight path and the white backdrop was $0.3 \mathrm{~m}$ further back creating a small parallax error, which was the same for all bees studied. We corrected for this by multiplying the measured velocity by $5 / 5.3=0.94$. We studied three nests of each species and recorded 89 individuals of $P$. helleri, 65 of $M$. scutellaris and 28 of $S$. depilis.

\section{Landing errors of bees approaching the entrance}

Some returning bees were unsuccessful at entering the nest. In P. helleri some bees hit and bounced out of the entrance or collided with the rim of the funnel. In $M$. scutellaris, collisions occurred with departing nestmates and in the crowded S. depilis entrance some bees fell off the rim. To quantify these errors, we set up the camera $4.0 \mathrm{~m}$ from the entrance at a horizontal angle of $45^{\circ}$ and zoomed in get a clear view, again recording at 200 FPS and a resolution of $320 \times 240$ pixels. We recorded 300 bees each for P. helleri and S. depilis and 200 for M. scutellaris (six nests per species) and then analysed the videos to determine the proportions of bees that successfully entered their nest versus those that made landing errors.

\section{Predation bioassay}

We tested the hypothesis that $P$. helleri accelerate on approaching the nest entrance to avoid ambush predation. We collected and freeze-killed jumping spiders (Salticidae) occurring naturally within $3 \mathrm{~m}$ of the $P$. helleri study colonies (Fig. 1b). Spiders were not identified to species, but varied in colour and in length from 5 to $10 \mathrm{~mm}$, excluding appendages. We applied a 'predator treatment' to colonies by placing four spiders on the outer entrance of a $P$. helleri nest, and compared the velocity of bees approaching these nests with those approaching control nests. We focussed on the distance at which we had identified velocity changes and measured velocity across small, $25 \mathrm{~mm}$, intervals filming at $220 \mathrm{FPS}$ and $320 \times 240$ pixels. We studied three nests and rotated the predator and control treatments around each. In total, we recorded 90 approaching bees under the predator treatment and 180 for controls ( $n=3$ nests, evenly divided per nest). We further examined whether any velocity changes resulted in increased errors as above. 


\section{Statistical analysis}

To address our primary hypothesis, does $P$. helleri enter its nest at greater velocity than related species with contrasting entrance structures, we compared velocity among the three species at the final interval, $0.1-0.0 \mathrm{~m}$ from the nest entrance. We used a mixed-effects model fitting velocity as the response variable, species as a fixed effect, and colony as a random effect.

We had no a priori knowledge of the scale at which velocity changes in $P$. helleri were likely to occur. Therefore, we fitted a segmented regression model of velocity against distance estimate the distance from the nest at which velocity changed. We then compared acceleration among species at distances before and after this point using a mixed-effects model, fitting acceleration as the response variable, a sixlevel factor containing each combination of species $(n=3)$ and distance $(n=2)$ as a fixed effect and colony as a random effect.

To analyse the error rate of bees among species (proportion of successful landings), we used a mixed-effects model with a binomial error structure fitting species as a fixed effect and colony as a random effect. For the predation bioassay, we compared bee velocity before and after identified points of velocity change using a mixed-effects model, fitting treatment (spiders versus control) as a fixed effect and colony as a random effect, and examined error rates using a mixed effects model with a binomial error structure. Reported test statistics are comparisons to the null model using ANOVA.

All statistical analyses were performed using R 3.1.1 ( $\mathrm{R}$ Core Team 2014) and the $\mathrm{R}$ packages 'Ime4' for mixedeffects models (Bates et al. 2015), 'segmented' for segmented regression (Muggeo 2008) and 'multcomp' for post hoc multiple comparisons (Hothorn et al. 2008). Data is available at https://zenodo.org/record/1310913\#.XO5el 9h7mUk.

\section{Results}

\section{Velocity and acceleration of approaching bees}

Partamona helleri and Melipona scutellaris both initially travelled at a similar velocity of approximately $2.0 \mathrm{~ms}^{-1}$ (Fig. 2). Scaptotrigona depilis was initially faster at $2.6 \mathrm{~ms}^{-1}$. However, sample sizes were low for $S$. depilis for distances $>1.0 \mathrm{~m}$ as most individuals were not yet aligned to their entrances, which led to less reliable estimates of velocity (Fig. 2). All S. depilis individuals had aligned by $0.7 \mathrm{~m}$, at which point it was the slowest of the three species. Approach velocities reduced for all three species as they neared the entrance. However, at $0.2 \mathrm{~m}$

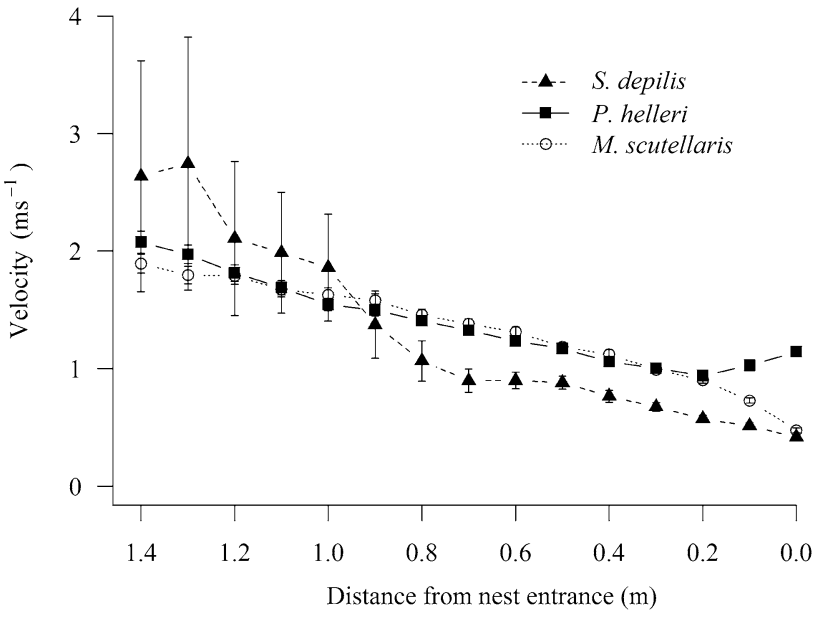

Fig. 2 Mean velocity of three stingless bee species as they approach their nest entrances. Each tick mark represents the $0.1 \mathrm{~m}$ interval over which velocity was measured. For example, $0.0 \mathrm{~m}$ refers to the $0.1-$ $0.0 \mathrm{~m}$ interval. Error bars \pm 1 standard error. $n=89,65$ and 28 for $P$. helleri, M. scutellaris and $S$. depilis, respectively

from the entrance, the velocity of $P$. helleri increased while it continued to decrease in the two other species. Partamona helleri workers collided with the entrance at $1.14 \mathrm{~ms}^{-1}$, over double that of the controlled landing in the other two species (Fig. 2). There were significant differences among species (mixed-effects model, $F=109.29$, $D F=2, P=0.003$ ), and post hoc Tukey tests revealed that $P$. helleri was significantly faster than $M$. scutellaris and S. depilis $(P<0.001$ in both cases) and that the latter two species did not differ $(P=0.799)$.

A segmented regression of $P$. helleri's approach to its nest entrance revealed a 'break point' of $0.24 \mathrm{~m}$. The break points for Melipona scutellaris and S. depilis were $0.24 \mathrm{~m}$ and $0.77 \mathrm{~m}$, respectively, although neither had the stark change in slope seen in $P$. helleri (Fig. 2). We then analysed the acceleration of bees either side of the nearest measurement point to the breakpoint of $P$. helleri, $0.2 \mathrm{~m}$. That is, we compared acceleration of $P$. helleri over $0.2-0.0 \mathrm{~m}$ from the entrance with $1.4-0.2 \mathrm{~m}$. We found significant differences in acceleration among species, and for greater versus less than $0.2 \mathrm{~m}$ from the entrance (mixed-effects model, $F=50.64, D F=5, \mathrm{P}<0.001$, Fig. 3). Post hoc tests showed no significant differences in acceleration among species at $1.4-0.2 \mathrm{~m}(P>0.05$ in all cases $)$. However, at $0.2-0.0 \mathrm{~m}$, the acceleration of $P$. helleri was significantly greater than that of the other species $(P<0.001$ in all cases $)$ and this was the only instance in which acceleration was positive. That is, $P$. helleri was accelerating within the final $0.2 \mathrm{~m}$ of approach, while both $S$. depilis and M. scutellaris continued to decelerate. Crucially, the acceleration of $P$. helleri over $0.2-0.0 \mathrm{~m}$ was significantly greater than over $1.4-0.2 \mathrm{~m}(P<0.001)$. This shows that as $P$. helleri approached the nest entrance, 


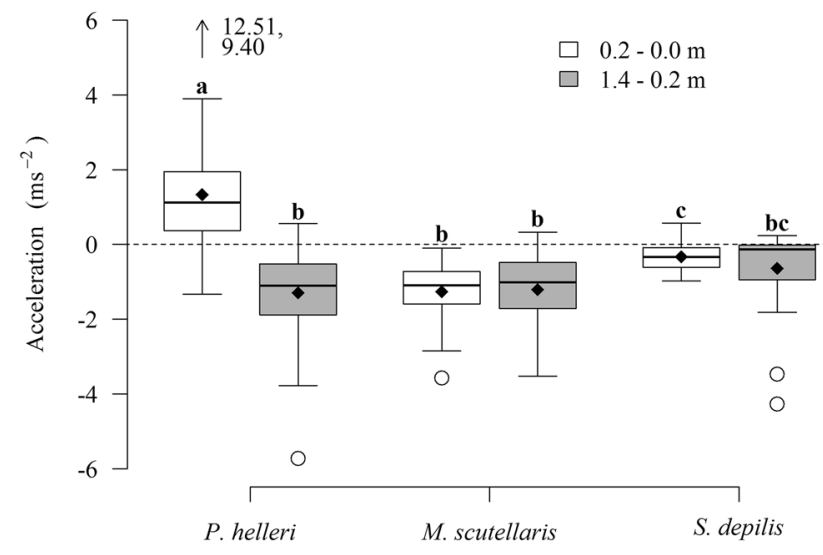

Fig. 3 Acceleration of three stingless bee species as they approach their nest entrances, measured before and after $0.2 \mathrm{~m}$ from the entrance. Letters show significant differences. Bars indicate $1.5 \times \mathrm{IQR}$, black diamonds show means, white circles and arrows show outliers, dashed line shows the boundary between acceleration and deceleration. $n=89,65$ and 28 for P. helleri, M. scutellaris and $S$. depilis, respectively

its acceleration switched from negative to positive. The other two species did not express this switch. P. helleri concluded its entry by crashing, head first, into the entrance (Video A1, A2).

\section{Landing errors of bees approaching the entrance}

The vast majority of individuals from all three species successfully landed or crash-landed at their nest entrance: 98.0, 96.5 and $91.5 \%$ for P. helleri, M. scutellaris and S. depilis, respectively ( $n=200$ per species). In the fast moving $P$. helleri, three bees hit the back of the outer entrance and bounced out of the entrance funnel rather than falling down and towards the inner entrance, while one bee hit the lip of the entrance, bouncing outwards. In the slower moving $M$. scutellaris, the landing of seven individuals was disrupted by traffic, either a nestmate attempting to enter simultaneously or colliding with an outward-bound bee. In S. depilis, the high density of guards posted around the entrance (Fig. 1c) hindered returning bees, such that there was little available space for them to land, resulting in 17 bees tumbling down from the entrance. Bee species did not differ significantly in the proportion of individuals successfully entering the nest (mixed-effects model, $\chi^{2}=2.93, D F=2, P=0.2311$ ).

\section{Predation bioassay}

The average velocity of $P$. helleri bees did not differ between spider and control treatments at $0.2-0.4 \mathrm{~m}$ from the nest (mixed-effects model, $F=1.50, D F=1, P=0.221$ ). However, in the final $0.2 \mathrm{~m}$, bees which approached nests with experimentally added spiders (predator treatment) had

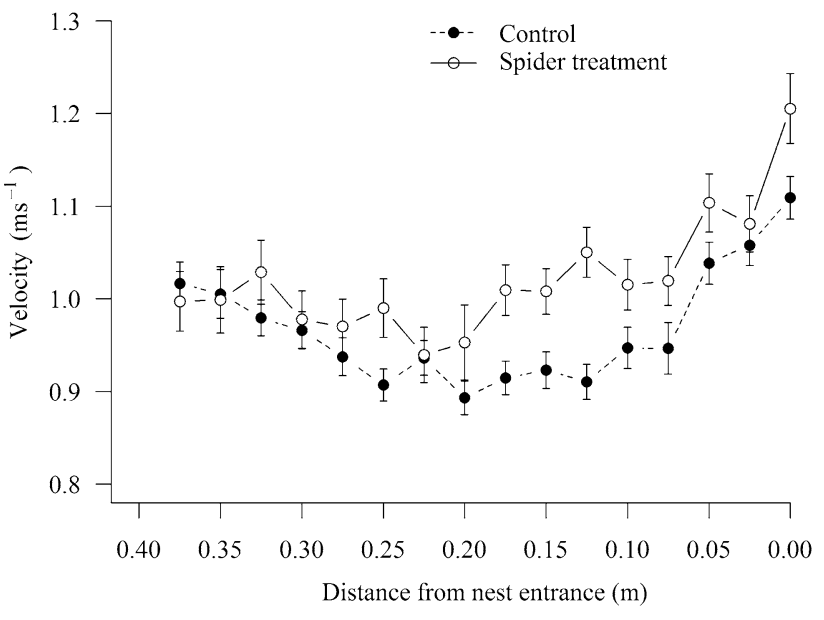

Fig. 4 Velocity of Partamona helleri stingless bee foragers approaching nests with and without the presence of predators, dead jumping spiders (Salticidae), placed on the outer edge of the entrance funnel. Error bars \pm 1 standard error. Each tick mark represents the $0.25 \mathrm{~mm}$ interval over which velocity was measured

significantly greater velocity than those approaching control nests, $1.21 \mathrm{~ms}^{-1}$ versus $1.11 \mathrm{~ms}^{-1}$, a $9 \%$ increase (mixedeffects model, $\chi^{2}=8.30, D F=1, P=0.004$, Fig. 4). This did not result in a reduction in accuracy, 98.0 vs $98.8 \%$ of control versus predator treatment bees successfully entered their nests (mixed-effects model, $\chi^{2}=0.798, D F=1, P=0.372$ ).

\section{Discussion}

Workers of Partamona helleri exhibit a distinct behavioural sequence as they approach their nest entrance. To an observer, returning P. helleri workers initially slow down and 'aim' themselves at the funnel entrance. Workers then accelerate such that they enter the nest at great speed, crash into the back wall of the funnel and ricochet down into the inner entrance. The ultimate result is that $P$. helleri workers enter their nest at a far greater velocity than species that use a conventional landing. The landing velocity of $P$. helleri workers was also four times lower than their departure velocity, which suggests that the maximum velocity of a returning worker is constrained by the need to slow and align itself with the entrance and the short distance over which it accelerates.

The increase in velocity of $P$. helleri workers in response to the addition of predators to the entrance suggests that bees were able to detect the spiders and exhibited an adaptive response. This provides support for our hypothesis that this remarkable behaviour has evolved to avoid ambush predation. Our results parallel those of Tan et al. (2007), who found that Apis cerana bees reduced predation from bee-hawking by Vespa wasps by increasing their entrance 
approach speed. The decision of a prey animal to dart into a refuge generally incurs a cost, because time spent in the refuge is time not spent foraging, and the decision to flee may alert the predator to the presence of cryptic prey (Ydenberg and Dill 1986; Broom and Ruxton 2005). However, social insect foragers do not typically employ crypsis and entry to the nest is already the desired objective. Rather, the costs of this behaviour would be borne at the colony level in the construction of the elaborate nest entrance, which is larger than those of other stingless bee species of similar colony size.

The size of a social insect nest entrance is a critical factor in a colony level trade-off between defence and foraging efficiency (Couvillon et al. 2008). However, our results suggest that individual-level predation may be a third component in this trade-off, in that large entrances require more guards to defend, allow a higher volume of forager traffic and also facilitate a faster landing velocity that reduces ambush predation. This raises the question of the relative importance of these three variables in driving the evolution of nest entrance structure. We maintain that colony-level defence and foraging are the greater selective pressures, because although an attack on the whole colony is rarer than predation on individual workers, the consequences could be the death of the whole colony (Ono et al. 1995), and indeed, P. helleri workers are aggressive in defence of their nest (Shackleton et al. 2015). A wider comparative study of entrance sizes, landing velocity and predation rates would be welcome in this regard.

Like other animals, social insects are subject to speed-accuracy trade-offs in many aspects of their biology, such as foraging decisions (Chittka et al. 2003, 2009; Burns and Dyer 2008). However, while $P$. helleri enters its nest at high velocity with no increase in landing errors, we cannot say that it is making a true speed-accuracy trade-off. Rather, the large nest entrance area alleviates the ecological pressure for $P$. helleri to be accurate. Furthermore, the back wall of the nest entrance may provide a visually contrasting target at which to aim (Chittka et al. 1997). In the narrow entrance of M. scutellaris and the crowded entrance of S. depilis, bees arriving sometimes collided with departing bees or with standing guards. Because $P$. helleri guards are stationed at the lower, inner entrance, the chance of collisions with other bees is also low. The costs of making a mistake are probably not great in terms of time lost, as it takes only a few seconds to reattempt entry. However, the costs of errors would be greater when predation pressure at the entrance is high, a greater penalty for missing the target.

The purpose of the crash and ricochet itself is not immediately clear, but may occur because a conventional landing is impossible at such speeds, or because it is the quickest way to enter the safety of the inner entrance. Larger animals that experience head impacts have evolved morphological adaptations to prevent damage (Gibson 2006; Farke 2008). Similarly, humans who engage in contact sports often wear protective headgear. However, we observed no external morphological protective features on $P$. helleri that would protect against a collision compared to the other species, although we cannot rule out internal adaptations. The low mass of $P$. helleri means that the forces experienced during a crash are probably small (Haldane 1926). In general terms, the damage caused by an impact is dependent on the kinetic energy (KE) of the object, which for a given velocity is proportional to its mass and the area over which the impact occurs. Mass scales as the cube of an object's length, whereas area scales as the square of an object's length. Small objects (bees) therefore have a lower mass per unit area than large objects (humans). As a result, impacts at speeds that could injure or kill a human are trivial for a bee.

Consider the forces acting on a crash-landing bee. The work per unit area required to break an item is its work of fracture (WoF), measured in joules per square metre (Vogel 2003). More damage results from higher energy applied over a smaller area. The WoF of insect cuticle $\left(1500 \mathrm{Jm}^{-2}\right)$ and bone $\left(1700 \mathrm{Jm}^{-2}\right.$ ) are similar (Vogel 2003). A bee with a velocity of $1.14 \mathrm{~ms}^{-1}$ and a mass of $0.0108 \mathrm{~g}$ has a KE of $7.0 \mathrm{E}-6 \mathrm{~J}$, spread across a head crosssectional area of $4.1 \mathrm{E}-6 \mathrm{~m}^{-2}$ (Table $\mathrm{S} 1$ ). The forces that the bee experience are thus $7.0 \mathrm{E}-6 / 4.1 \mathrm{E}-6=1.7 \mathrm{Jm}^{-2}$, far below its WoF. A $62 \mathrm{~kg}$ human travelling head first into a wall at the same velocity has a KE of $40.3 \mathrm{~J}$ spread across a head cross-sectional area of $2.25 \mathrm{E}-2 \mathrm{~m}^{2}$ giving $1791.1 \mathrm{Jm}^{-2}$, slightly higher than the WoF of bone, and 1000 times greater than that of bee. Alternatively, consider that a $62 \mathrm{~kg}$ human with equal KE to the bee would travel at $0.000475 \mathrm{~ms}^{-1}$, over 2000 times slower than the bee. A head impact at this velocity is not even painful. These crude calculations do not characterize every aspect of the collision, such as its elasticity or soft tissues that may cushion the impact. However, this does suggest that despite the drastic evolutionary change in the landing behaviour of $P$. helleri, no corresponding morphological adaptation is required.

Acknowledgements KS's PhD is jointly funded by the National Environment Research Council (Grant number: NE/K501347/1) and the University of Sussex School of Life Sciences and received travel funds from the Royal Entomological Society. HAT's PhD is funded by the University of Damascus. NJB's PhD is funded by Waitrose Ltd. and the C.B.Dennis Trust. HAT and NJB received travel funds from Santander Bank. FLWR received travel funds from the Fundação de Amparo à Pesquisa do Estado de São Paulo (Grant numbers: 2014/251365 and 2016/22861-6) and from Santander Bank. DDA is funded by the Programa Nacional de Pós-Doutorado da Coordenação de Aperfeiçoamento de Pessoal de Nível Superior. We would like to thank Luis C. Marchini and Julio Pupim for the use of hives and research facilities, 
Matthew Jesse for help processing video footage and the editor and two anonymous reviewers for their constructive feedback.

Open Access This article is distributed under the terms of the Creative Commons Attribution 4.0 International License (http://creativeco mmons.org/licenses/by/4.0/), which permits unrestricted use, distribution, and reproduction in any medium, provided you give appropriate credit to the original author(s) and the source, provide a link to the Creative Commons license, and indicate if changes were made.

\section{References}

Barber I, Nairn D, Huntingford FA (2001) Nests as ornaments: revealing construction by male sticklebacks. Behav Ecol 12:390-396

Bates D, Maechler M, Bolker B, Walker S (2015) Fitting linear mixedeffects models using lme4. J Stat Softw 67:1-48

Broom M, Ruxton GD (2005) You can run-or you can hide: optimal strategies for cryptic prey against pursuit predators. Behav Ecol 16:534-540

Burns JG, Dyer AG (2008) Diversity of speed-accuracy strategies benefits social insects. Curr Biol 18:R953-R954

Camargo JMF, Pedro SRM (2003) Neotropical Meliponini: the genus Partamona Schwarz, 1939 (Hymenoptera, Apidae, Apinae)bionomy and biogeography. Revista Brasileira de Entomologia 47:311-372

Chittka L, Schorn J, de Souza M, Ventura DF, Camargo JMF (1997) The nest entrance signal of Amazonian bees Partamona pearsoni-case where insects design their own flight targets. Proceedings of the International Collquiua on Social Insects, V.E. Kipyatkov (Ed.), Russian Language Section of the IUSSI Socium, St. Petersburg, 3-4:107-116

Chittka L, Dyer AG, Bock F, Dornhaus A (2003) Psychophysics: bees trade off foraging speed for accuracy. Nature 424:388

Chittka L, Skorupski P, Raine NE (2009) Speed-accuracy tradeoffs in animal decision making. Trends Ecol Evol 24:400-407

Couvillon MJ, Wenseleers T, Imperatriz-Fonseca VL, Nogueira-Neto P, Ratnieks FLW (2008) Comparative study in stingless bees (Meliponini) demonstrates that nest entrance size predicts traffic and defensivity. J Evol Biol 21:194-201

Evangelista C, Kraft P, Dacke M, Reinhard J, Srinivasan MV (2010) The moment before touchdown: landing manoeuvres of the honeybee Apis mellifera. J Exp Biol 213:262-270

Farke AA (2008) Frontal sinuses and head-butting in goats: a finite element analysis. J Exp Biol 211:3085-3094

Gibson LJ (2006) Woodpecker pecking: how woodpeckers avoid brain injury. J Zool 270:462-465

Haldane JBS (1926) On being the right size. Harper's Magazine, New York

Hansell M (2007) Built by animals. Oxford University Press, Oxford

Hölldobler B, Wilson EO (1990) The ants. Harvard University Press, Cambridge

Hothorn T, Bretz F, Westfall P (2008) Simultaneous inference in general parametric models. Biom J 50(3):346-363

List C, Elsholtz C, Seeley TD (2009) Independence and interdependence in collective decision making: an agent-based model of nestsite choice by honeybee swarms. Philos Trans R Soc B Biol Sci 364:755-762
MacKay WP (1982) The effect of predation of western widow spiders (Araneae: Theridiidae) on harvester ants (Hymenoptera: Formicidae). Oecologia 53:406-411

Michener CD (2000) The bees of the world. Johns Hopkins University Press, Baltimore

Muggeo VMR (2008) Segmented: an R package to fit regression models with broken-line relationships. R News 8/1:20-25. https:// cran.r-project.org/doc/Rnews/

Ono M, Igarashi T, Ohno E, Sasaki M (1995) Unusual thermal defence by a honeybee against mass attack by hornets. Nature 307:334-336

Roubik DW (2006) Stingless bee nesting biology. Apidologie $37: 124-143$

R Core Team (2014) R: a language and environment for statistical computing. R Foundation for Statistical Computing, Vienna, Austria. http://www.R-project.org/

Schatz B, Wcislo WT (1999) Ambush predation by the ponerine ant Ectatomma ruidum roger (Formicidae) on a sweat bee Lasioglossum umbripenne (Halictidae), in Panama. J Insect Behav 12:641-663

Seeley TD (2010) Honeybee democracy. Princeton University Press, Princeton

Shackleton K, Toufailia HA, Balfour NJ, Nascimento FS, Alves DA, Ratnieks FLW (2015) Appetite for self-destruction: suicidal biting as a nest defense strategy in Trigona stingless bees. Behav Ecol Sociobiol 69:273-281

Srinivasan MV, Zhang SW, Chahl JS, Barth E, Venkatesh S (2000) How honeybees make grazing landings on flat surfaces. Biol Cybern 83:171-183

Tan K, Radloff SE, Li JJ, Hepburn HR, Yang MX, Zhang LJ, Neumann P (2007) Bee-hawking by the wasp, Vespa velutina, on the honeybees Apis cerana and A. mellifera. Naturwissenschaften 94:469-472

van Casteren A, Sellers WI, Thorpe SKS, Coward S, Crompton RH, Myatt JP, Ennos AR (2012) Nest-building orangutans demonstrate engineering know-how to produce safe, comfortable beds. Proc Natl Acad Sci USA 109:6873-6877

van Damme R, van Dooren TJM (1999) Absolute versus per unit body length speed of prey as an estimator of vulnerability to predation. Anim Behav 57:347-352

Visscher PK (2007) Group decision making in nest-site selection among social insects. Annu Rev Entomol 52:255-275

Vogel S (2003) Comparative biomechanics. Princeton University Press, Princeton

Wallace AR (1867) The philosophy of birds' nests. Intellect Obs 11:413-420

Wenseleers T, Bacon JP, Alves DA, Couvillon MJ, Kärcher M, Nascimento FS, Nogueira-Neto P, Ribeiro M, Robinson EJH, Tofilski A, Ratnieks FLW (2013) Bourgeois behavior and freeloading in the colonial orb web spider Parawixia bistriata (Araneae, Araneidae). Am Nat 182:120-129

Ydenberg RC, Dill LM (1986) The economics of fleeing from predators. In: Rosenblatt JS, Beer C, Busnel MC, Slater PJB (eds) Advances in the study of behavior. Academic Press, Cambridge, pp 229-249

Zacarias F, Youtube user "Abelhas e Vespas Nativas TV" (2015) Tropidurus spp. lizards predating on Partamona helleri workers https ://www.youtube.com/watch?v=SAWLpXx2U2s. Accessed 08 Jan 2018 